\title{
"Expressions of personhood in Alzheimer's disease": An evaluation of research-based theatre as a pedagogical tool
}

\author{
Kontos, P., Naglie, G. \\ Version Post-Print/Accepted Manuscript \\ Citation Kontos, P., Naglie, G. "Expressions of personhood in Alzheimer's \\ (published version) disease": An evaluation of research-based theatre as a pedagogical tool. \\ Qualitative Health Research 2007; 17(6):799-811 \\ Publisher's Statement This is the peer reviewed version of the article, which has been \\ published in final form at \\ http://dx.doi.org/10.1177/1049732307302838.
}

Always cite the published version, so the author(s) will receive recognition through services that track citation counts, e.g. Scopus. If you need to cite the page number of the TSpace version (original manuscript or accepted manuscript) because you cannot access the published version, then cite the TSpace version in addition to the published version using the permanent URI (handle) found on the record page. 


\title{
"Expressions of personhood in Alzheimer's disease": An evaluation of research-based theatre as a pedagogical tool
}

\author{
By ${ }^{1}$ Pia C. Kontos and ${ }^{2}$ Gary Naglie
}

C Pia C. Kontos ${ }^{1}$ \& Gary Naglie ${ }^{2}, 2006$

${ }^{1}$ Pia C. Kontos, BA, MA, PhD

Postdoctoral Fellow

Toronto Rehabilitation Institute

11035-550 University Ave.

Toronto, ON M5G 2A2

Canada

TEL: (416) 597-3422, ext. 7609

FAX: (416) 597-7105

Email: kontos.pia@torontorehab.on.ca

${ }^{2}$ Dr. Gary Naglie

Mary Trimmer Chair in Geriatric Medicine Research,

University of Toronto

Associate Professor, Departments of Medicine,

and Health Policy, Management and Evaluation,

University of Toronto

Consultant Geriatrician and Senior Scientist,

Toronto Rehabilitation Institute and University Health Network

Toronto Rehabilitation Institute

1008-550 University Ave.

Toronto, ON M5G 2A2

Canada

TEL : (416) 597-3422 ext. 3834

FAX: (416) 597-7105

Email: naglie.gary@torontorehab.on.ca 


\begin{abstract}
A growing number of scholars are turning to dramatic performance as an innovative approach to disseminating the results of qualitative research. With an interest in this aesthetic practice, we transformed ethnographic research on personhood in Alzheimer's disease into a dramatic production, Expressions of Personhood in Alzheimer's that was performed at the outset of focus group discussions with health practitioners. In this paper we report the results of an evaluation of health practitioners' perceptions of this theatrical adaptation as a pedagogical tool. Data from the focus group discussions and a self-administered post-performance survey suggest that there was a perceived relevance of the production to practitioners' own practice, an increased understanding gained from attending the production, and a strong endorsement of the use of drama as an educational tool for disseminating information about dementia care.
\end{abstract}

\title{
Keywords
}

Alzheimer's disease

Personhood

Drama

Research dissemination 


\section{Introduction}

There has been a recent upsurge of interest in the use of drama for the dissemination of qualitative social science research. An alliance between the aesthetic of performance and the methodological and theoretical ambitions of research has been forged, an alliance that has largely been fuelled by the recent emphasis on knowledge translation (Gray, Fitch, Labrecque, \& Greenberg, 2003). Most major funding organizations now require that knowledge creation projects must also include strategies to accelerate the application of research findings. This is exemplified in the mandate of the Canadian Institutes of Health Research $(\mathrm{CIHR})^{1}$ that was established by an act of Parliament (Norris \& Madore, 2000). The Canadian Institutes of Health Research Act defines the objectives of CIHR as to excel in the creation of new knowledge and to translate that knowledge from the research setting to real-world applications in order to provide more effective health services and to improve the health of Canadians.

The emphasis on research utilization has turned the very activity of knowledge translation into a subject of research in order to identify the most effective strategies to promote the communication of findings to various audiences. Increasingly, researchers are recognizing that the printed word and lectures are not always the most effective strategy to support learning (Bero, Grimshaw, Harvey, Oxman, \& Thomson, 1998). Narrative, drama and other arts-based approaches lend themselves particularly well to "humanistic teaching" (Lorenz, Steckart, \& Rosenfeld, 2004; Nussbaum, 1997, 2004). Within the context of medical education, Charon et al. (1995) assert that studying literature (e.g. fiction, poetry, etc.) helps clinicians attend to the human dimensions of medicine, to understand patients' experiences of sickness, to recognize the clinician's role in alleviating suffering, and to appreciate the power of the patient-clinician relationship. Shapiro and Hunt contend (2003, p. 923) that live theatrical performances 
contribute significantly to medical education because they have "a uniquely compelling emotional quality, making it difficult to avoid or intellectualize the struggles and suffering portrayed". Literature and theatre have long been a means of humanizing medical education (Acuna, 2000). Dramatic performances have been successful in helping practitioners and medical trainees reflect on the care they provide and increase their understanding of patient care issues (Gray et al., 2003; Lorenz et al., 2004; Rosenbaum, Ferguson, \& Herwaldt, 2005; Shapiro \& Hunt, 2003). For example, in post-performance evaluations of No Big Deal? (Gray et al., 2003), a production based upon a study about the experiences of men with prostate cancer and their spouses, physicians, nurses, and allied health professionals indicated that attending the performance resulted in a new level of awareness or understanding of how patients are affected by cancer diagnosis and treatment. Deloney and Graham (2003) have similarly validated the use of theater as an effective method to provide training about end-of-life issues and doctor-patient communication. Such validation suggests that research-based drama, in communicating research findings more directly and effectively to health professionals, can change attitudes, and, in doing so, holds the potential to change practice as well (Gray et al., 2003).

A growing number of qualitative health researchers are turning to theatrical performance as an innovative approach to extending research findings beyond the discipline in which they were generated and thereby making research more accessible and relevant in health care settings (Gray, Sinding, \& Fitch, 2001; Gray et al., 2000; Kontos \& Naglie, 2006; Mienczakowski, 1999; Nisker, Martin, Bluhm, \& Daar, 2006; Paget, 1993; Sandelowski, Trimble, Woodard, \& Barroso, 2006). This use of theatre is appropriately termed "health theatre" (Mienczakowski, Smith, \& Morgan, 2002, p. 35) since it predominantly targets "health audiences" (health consumers, carers of health consumers, health professionals, and health educators). Research-based productions 
about schizophrenia (Mienczakowski, 1992), substance abuse (Mienczakowski \& Morgan, 1993), breast cancer (Gray et al., 2000; Sinding, Gray, Fitch, \& Greenberg, 2002), prostate cancer (Gray et al., 2003), ovarian cancer (Shapiro \& Hunt, 2003), AIDS (Shapiro \& Hunt, 2003), and Alzheimer disease (Kontos \& Naglie, 2006) are some examples of "health theatre".

Expressions of Personhood in Alzheimer's (Kontos \& Naglie, 2006) is a research-based production about self-expression through habits, gestures and actions of the body by residents in advanced stages of Alzheimer's disease living in a long-term care facility ${ }^{2}$. The production was performed live at the outset of focus groups with health care practitioners and served as a springboard for discussion about the importance of recognizing and supporting bodily expressions of personhood for person-centred dementia care.

The purpose of this article is to report upon and provide commentary about an evaluation of health care practitioners' perceptions of the effectiveness of the research-based production in conveying the meaning and significance of bodily habits, gestures and actions in the context of advanced stages of Alzheimer's disease. Data from focus groups with health care practitioners and a self-administered post-performance survey will be discussed. We begin with a brief critique of person-centred dementia care in order to contextualize the research upon which Expressions of Personhood in Alzheimer's is based and our rationale for translating the findings of this research into a dramatic performance.

\section{Person-centred dementia care: A critique}

Much of the literature on Alzheimer's disease promotes the view that individuals with dementia experience a steady erosion of selfhood to the point at which no person remains (Kitwood \& Benson, 1995). The self is thought to be increasingly devoid of content, a process that has been referred to as "unbecoming" a self (Fontana \& Smith, 1989), and a "drifting 
towards the threshold of unbeing" (Kitwood \& Bredin, 1992, p. 285). As a corrective to the depersonalizing tendencies of some caregiving practices and treatment contexts, the principles of person-centred care have been widely espoused in a range of care environments (Henderson \& Vesperi, 1995; Kitwood, 1997; Nolan, Booth, \& Nolan, 1997; Williams \& Grant, 1998), but it is in relation to dementia care ${ }^{3}$, particularly in the work of Kitwood $(1990 ; 1992 ; 1993 ; 1995 ; 1997$; 1998), that person-centred care has been fully articulated. Kitwood's notion of personhood is influenced largely by a social interactionist perspective (Golander \& Raz, 1996; Kitwood, 1997; Lyman, 1989, 1998; Sabat \& Harré, 1992). One of the key ideas of interactionist social theory is that the nature of the self is social in that its existence hinges on social interaction (Cooley, 1972; Goffman, 1963; Mead, 1970). Kitwood (1997, p. 8), for example, defines personhood as “a standing or status that is bestowed upon one human being by others, in the context of relationship and social being"; personal affirmation provided by quality psychological contact is thus essential for the maintenance of personhood. Conceptualizing personhood in this way challenges the notion that the personal deterioration associated with dementia comes about exclusively as the result of a neurological process that has its own autonomous dynamic.

Kitwood (1990) argues that interactions that tend to depersonalize the sufferer of Alzheimer's disease, what he terms "malignant social psychology", is integral to the downward process of dementia. It is precisely for this reason that he argues that as the ability to manifest agency becomes impaired due to increased neuropathology, selfhood needs to be sustained increasingly by the facilitation of others. Where care providers fail to attend to the subjectivity of those with dementia, what Kitwood refers to as "unattended dementia", the inevitable result will be "a dismantling of personality, a loss of self' (quoted in Morton, 1999, p. 105). 
Embracing a view of personhood that hinges on social interconnectedness provides a crucial critique of the dominant paradigm of dementia that makes the assumption that with the onset and progression of Alzheimer's disease there is a complete loss of self (Davis, 2004). However, to maintain that it is the socio-interactive environment alone that constitutes selfhood in dementia is to miss the significance of "embodied selfhood" (Kontos, 2004, 2005, 2006a)the idea that bodily habits, gestures, and actions support and convey humanness and individuality.

Embodied selfhood emphasizes the corporeal nature of our being that exists below the threshold of cognition, and thus persists despite even severe cognitive impairment (Kontos, 2004, 2005, 2006a). This concept takes its theoretical bearings from Merleau-Ponty's phenomenological understanding of non-representational intentionality and the primordial body (1962), and Bourdieu's concept of "habitus" (1977; 1990), which links bodily dispositions to socio-culturally specific conditions of primary socialization (for a more lengthy discussion of these ideas see Kontos, 2006b). Kontos claims that selfhood has two origins. The first is primordial, whereby selfhood emanates from the body's power of natural expression, and manifests in the body's inherent ability to apprehend and convey meaning. The second is the socio-cultural dimension of the pre-reflective body that derives from the culture-specific conditions of one's primary socialisation. Such conditions give socio-cultural specificity to selfhood by virtue of being embodied and materialised in our habitual state, tendencies and inclinations to act in particular ways. Kontos conceptualizes the body's power of natural expression as the foundation of selfhood in that it not only makes possible the internalization of socio-cultural dispositions, but continuously impels and sustains socio-cultural manifestations of selfhood (Kontos, 2006b). 
With mounting empirical evidence that person-centred approaches to care facilitate the achievement of positive health outcomes and enhance quality of life (Allen-Burge, Stevens, \& Burgio, 1999; Brodaty, 1996; Brodaty, Green, \& Koschera, 2003; Dröes, 1997; Finnema, Dröes, Ribbe, \& Tilburg, 2000; Fossey et al., 2006; Haupt, Karger, \& Jänner, 2000; Sloane et al., 2004), it is clear that the maintenance of personhood ought to be central to dementia care. Though the need for person-centred approaches to dementia care is widely advocated (Jonas-Simpson, 2001;

Kitwood, 1997; Tappen, Williams, Fishman, \& Touhy, 1999), it is our contention that personhood itself must be understood as embodied for dementia care to truly become personcentred. The consequences of overlooking embodied selfhood are most significant in the context of dementia care, because in cases of severe cognitive impairment, the body becomes the primary means of self-expression (Kontos, 2004, 2005).

\section{Performing the data}

As a first step towards the development of dementia care practices premised on the notion of embodied selfhood, we designed a study to conduct focus groups with health care practitioners with the objective to explore with them the breadth and importance of nonverbal self-expression by persons with severe cognitive impairment as well as how their recognition and support of such self-expression could enhance person-centred dementia care. Conveying ethnographic research about self-expression through bodily habits, gestures, and actions (Kontos, 2004, 2005) would enrich the discussion and further facilitate the achievement of our study objective. However, we found that it would be difficult to disseminate this research effectively through traditional means of knowledge translation (oral presentation, textual materials, etc.) because of the limits of textualism (Abma, 2002). As noted for example by Clifford $(1986 ; 1988)$ and Conquergood (1991), the dynamic, intimate, precarious and embodied experiences observed 
in ethnographic fieldwork become one-dimensional in their textual representation. In contrast, dramatizing the data recovers the experiences previously represented in the ethnographer's text and then re-presents those experiences as embodied performance (Denzin, 1997). This "doubling back" on the original ethnographic experiences of direct involvement in people's daily lives -observing them and interacting with them, learning how they respond to situations, how they organize their lives, etc. -- recovers the textures, sounds, gestures, and movements of the lived world which get lost in the translation of participant observation into textual documentation. Our rationale for translating Kontos' ethnographic research findings into dramatic form was that performance would provide the focus group participants with a more vivid depiction of how selfhood is manifested in habits, gestures and actions of the body than could be achieved with traditional dissemination strategies (Kontos \& Naglie, 2006).

A further rationale for using drama to translate these research findings was its potential to move audiences to critical awareness, as argued by Denzin (1997), and to encourage reflection on care giving practices. Expressions of Personhood in Alzheimer's is a production that not only re-presents embodied expressions of selfhood in Alzheimer's disease, but also critically exposes depersonalizing tendencies of some caregiving practices that are a consequence of either an assumed loss of selfhood that is widely associated with the cognitive deficiencies that lie at the core of dementia or a narrow perspective on personhood that does not account for the role that the body plays in its manifestation. The dramatic portrayal of interactions between staff and individuals with Alzheimer's disease would facilitate the focus group participants' recognition and reflection regarding opportunities for health care staff to respond to and support the selfhood of persons with cognitive impairment in its embodied manifestations. 
The production itself consisted of five separate vignettes, which were thematically connected in that all featured bodily expressions of selfhood by severely cognitively impaired residents of an Alzheimer Support Unit. These were actual observed occurrences drawn from ethnographic research on an Alzheimer Support Unit (Kontos, 2004). The following five instances of actual observed occurrences served as the basis for the scripts of the vignettes: 1) a female resident struggles to pull out a string of pearls from underneath her bib so that they could be seen by the other residents seated at her table without the staff ever responding to her proud display of her pearls; 2) a resident who has no recollection of her talent to weave repeats "I cannot" as a program instructor demonstrates for her how to weave a canvas, but once a threaded needle is placed between her fingers she proceeds to weave with proficiency; 3) a resident who sees another resident seated at the dining table alone with her breakfast untouched gestures for her to eat as she peels for her the hard boiled egg and removes the foil lid of her juice; 4) a resident believes that her deceased husband to whom she was married for 65 years has just died, and she gestures to a nurse who tries to console her to "sit Shiv'ah" with her (the Jewish ritual of prescribed mourning following the death of a parent, spouse or child), and the nurse does; and 5) on the eighth day of Hanukkah a party is organized for the residents and following the celebratory lighting of the Menorah, when staff begin to take the residents back to the unit, one resident resists and, while staff are busy tending to other residents, she slowly makes her way across the room in her wheelchair to where the Menorah stands, and she covers her eyes and whispers a prayer to herself.

The production remained faithful to these "in life" scenes precisely because they so powerfully render visible how selfhood is expressed through the body: selfhood as an expression of distinction, creativity, genuine caring, and as expressed through the re-enactment of a ritual 
practice, despite even severe cognitive impairment ${ }^{4}$. These observed occurrences were re-enacted in the production in order to offer insight and stimulate discussion amongst the focus group participants about the breadth and importance of nonverbal communication for self-expression by persons with severe cognitive impairment. The translation of the ethnographic research into dramatic form involved partnership with ACT II Studio, a theatre school and creative drama centre for older adults, at Ryerson University's G. Raymond Chang School of Continuing Education, Toronto, Canada. ACT II Studio has a demonstrated history of developing socially relevant dramas for public presentation.

\section{Methods}

Six focus groups were conducted in three different academic health care facilities, located in an urban region of Ontario, Canada. Given the pioneering nature of our research, the focus group technique was the most appropriate method since it provides a vehicle for exploratory research in areas in which little is known about a phenomenon (Easton, 1999). A discussionoriented format helps participants navigate issues and promotes the articulation of ideas, where comments of one participant will prompt other participants to share their thoughts and experiences. This interactive dynamic creates an atmosphere that fosters collaborative learning and has the potential to yield richer data than what could be obtained from one-on-one interviews (Kitzinger, 1995; Krueger \& Casey, 2000) The participating facilities provide a range of programs and services including acute inpatient care, outpatient care, complex continuing care, long-term care, and rehabilitation, and were chosen because they specialize in the care of persons with dementia. The ethics review board of each of the three health care facilities involved in the study provided the necessary approval. Based on eligibility criteria provided by the principal investigator (see below), the appropriate administrators (manager, clinical nurse specialist, 
advanced practice leader, etc.) of each institution identified participants who, in their assessment, were deemed eligible. Those deemed eligible and who agreed to be contacted by the principal investigator were contacted by telephone, informed of the purpose of the focus groups, and were asked if they were willing to participate. Informed consent was obtained from all participants who were contacted.

A purposive sampling strategy (Denzin, 2000) was used to select the participants involving the following criteria for participant eligibility: 1) a nurse, health care aide, occupational therapist, physiotherapist or recreational therapist; 2) experience in providing "hands-on" care (e.g. bathing, dressing, feeding, rehabilitation) to patients or residents diagnosed with dementia; and 3) practice in accordance with a person-centred approach to care. The rationale for eligibility was that including health care practitioners of various disciplinary and clinical backgrounds would bring a diversity of experience that would broaden and enrich the focus group discussions. Also, the practice of these particular health care practitioners focuses on the body as the primary site of care work ${ }^{5}$. It is precisely the physical nature of their clinical practice that provides them the experience that would be crucial to the body-based perspective on personhood that we wished to explore. Recreational therapists were included given that in the activities they organize (exercise, music, social tea, etc.) they would have close proximity to residents which would provide them opportunities to observe residents' bodily habits, gestures and actions. Finally, those practitioners who adopt a person-centred approach to their dementia practice would be more likely to recognize that the recipients of their care, irrespective of their degree of cognitive impairment, are persons. Such recognition would be indispensable for a discussion about self-expression in Alzheimer's disease and how the recognition and support of such expression is critical for person-centred dementia care. 
Each focus group consisted of six to eight practitioners on staff at the given facility, with two focus groups conducted per facility. Forty-three practitioners, all of whom were female, participated; sixteen nurses, ten occupational therapists, eight physiotherapists, seven recreational therapists, and two health care aides. There were fewer health care aides because two of the three facilities do not staff this category of practitioner. Participants were recruited from long-term care (67\%), behavioural management (26\%), and geriatric rehabilitation (7\%) units that varied in size (10-bed to 79-bed units) and client/staff ratio (3:1 to 7:1).

The focus groups were each approximately ninety minutes in duration: thirty minutes for live performance of the production followed by sixty minutes for discussion. The discussion was based on a series of semi-structured questions about participants' perceptions of the production, specifically their understanding of self-expressions by persons with severe cognitive impairment through their bodily habits, gestures and actions and the response or lack of response by the care practitioners depicted in the production. Participants were invited to compare and contrast what was depicted in the production with their own experiences in order to explore self-expressions by persons with severe Alzheimer's in the context of their practice and the implications of recognizing, or not recognizing, such self-expressions for dementia care ${ }^{6}$.

A self-administered questionnaire was distributed at the end of each focus group for participants to complete ${ }^{7}$. The content of the questionnaire was developed based on a review of the literature and with consultation from social and health scientists with expertise in evaluating research-based theatre. The following five questions employed a five-point Likert response format ('strongly agree', 'agree', 'neutral', 'disagree', or 'strongly disagree'): 1) the play reminded me of experiences from my own clinical practice; 2) the play raised my awareness of the different ways that patients with Alzheimer's disease express themselves; 3) the play raised 
my awareness of the ways in which I interact with patients with Alzheimer's disease; 4) the play made me aware of the need for staff to recognize and respond positively to patients' bodily movements and gestures in the context of dementia care; and 5) I think that using research-based drama would be an effective way of educating staff about caring for patients with Alzheimer's

disease. Two-open-ended questions followed: 1) what was most helpful and/or interesting about the play, and why?; and 2) what was least helpful and/or interesting about the play, and why?

\section{Analysis}

All focus groups were audio-taped and transcribed. All data were analyzed according to standard thematic analysis techniques (Denzin \& Lincoln, 1998). Descriptive codes of analysis were first attached to segments of the text (Kuckartz, 1995). The descriptive codes were then grouped into broad topic-oriented categories and all text segments belonging to the same category were compared (Kuckartz, 1995). Ultimately, the topic-oriented categories were further refined and formulated into fewer analytical categories through an inductive, iterative process of going back and forth between the data and our conceptual framework of embodied selfhood. The focus group facilitator and the research assistant independently identified emerging themes which they then agreed upon through discussion. Data analysis was conducted concurrently with data collection, a process referred to as interim analysis (Miles \& Huberman, 1984), which allowed for confirmation, modification, or rejection of emerging themes as new transcripts were analyzed (Pope, Ziebland, \& Mays, 2000). Response frequencies were calculated for each of the Likert-type questions of the survey and the open-ended comments of the survey, given their qualitative nature, were analyzed for their descriptive content and meaning. 


\section{Findings}

\section{Focus group data}

The purpose of the focus groups was to explore the importance of nonverbal selfexpression by persons with severe cognitive impairment and how the recognition and support of such self-expression could enhance person-centred dementia care. Here we present pertinent excerpts from the focus group transcripts to illustrate the effectiveness of the theatrical performance in communicating the breadth and significance of self-expressions by persons with severe Alzheimer's disease. The qualitative data is organized thematically under the headings "Connecting to their own experience: Recognizing socially acquired habits of the body" and "Raised awareness of the significance of ritual and ceremony".

Connecting to their own experience: Recognizing socially acquired habits of the body

In reflecting on ways in which selfhood is expressed through gestures of the body by their own care recipients, many of the participants referred to the scene of the play where a cognitively impaired woman pulls a string of pearls from beneath her bib so that they can be seen by the other residents at the dining table. For example, a recreational therapist recounted the importance of hats for the residents of a Veterans' facility:

Hats. I find that hats, because I do a lot of outings, you know, it's like, 'oh, we got to wear a hat'. They're used to wearing a hat to go out, and then we enter a building, off comes the hat, you know. And I used to do a lot of Legion trips. If anyone wore a hat to go into a Legion, they had to buy everybody a round of beer. So you see, once they're coming in, oops, there goes the hat, you know. So some of those things that they've grown up with or have done their whole life stay with them. The scene with the pearls made me think of that. Just as she probably always has worn her pearls these men always have removed their hats in a Legion. It's part of who they are and how that is expressed.

Again, the same scene depicting the woman with her pearls prompted a health care aide to recount the following incident in the dining room of her facility: 
We have a resident like the woman with her pearls who is so nice and proper. I remember one time at breakfast, or maybe it was lunch, I can't remember, but what happened was a man burped so loud and a woman seated at his table was disgusted. She gave him a look I'll never forget and just like that she got up and left the table. She know [sic] you don't behave like that at the table. I said to myself 'what a proper lady'.

The health care aide clearly recognized the resident's respect for social conventions in her disapproval of the improper behaviour of the male resident seated at her table. Both the hats example above and the example of burping demonstrate how one's primary socialisation and cultural environment give selfhood its socio-cultural specificity by virtue of being embodied and materialised in one's habitual tendencies and inclinations to act in particular ways. The recreational therapist and health care aide clearly recognized these behavioural propensities as signifying selfhood.

Reflection on the ways in which care recipients manifest social etiquette continued with discussion about other social modes of expression by persons with dementia. For example, some participants recounted instances where a person's previous vocation instilled bodily dispositions to move and act in particular ways, and how, with some knowledge of the life history of those persons, they could recognize the meaning of such expressions. Reflecting on a scene of the play that depicts a female resident helping another resident eat her breakfast, an occupational therapist spoke of a resident who continued to express her previous vocation as a stay-at-home mother through bodily movement and behaviour:

She's always wanting to help. I see her going into the kitchen all the time to fold the bibs which usually sit in a pile there. She often tries to clear the dishes from her table when everyone is finished eating. She scrapes and stacks the dishes but kitchen staff make sure she doesn't carry them into the kitchen in case she drops them. Oh, I've also seen her follow the maintenance guy who cleans the carpets with that big machine. In the creative arts program she's picking up beads that have fallen on the floor. The woman in the play who sees that the other resident isn't eating her breakfast automatically wants to feed her. This client of mine would have done the same thing. It's as if they are still in their previous position or role from before they got Alzheimer's. She's a mom so making sure everyone is fed is important. 
The same scene prompted another participant, a nurse, to reflect on how one's previous vocation can be expressed through the body:

One of our residents was a policeman so he's always pacing up and down the hallway peering into bedrooms and sometimes it even looks as though he's holding a flashlight although he isn't really. He's making sure there isn't any suspicious behaviour on the unit.

These examples demonstrate the durability of the effects of socialization through cumulative exposure to certain social conditions associated with particular vocations. Just as dispositions are embodied, so too is selfhood, which the nurse and occupational therapist in the above examples recognized as manifest in the socio-culturally specific ways that the residents moved and behaved.

Creativity was yet another social mode of expression discussed. In reflecting on a scene of the play that depicts a female resident's ability to weave in the absence of any cognitive awareness of this ability, many participants understood this expression of creativity to be a manifestation of selfhood. As a nurse commented:

I can think of one of my residents who is resistive, difficult to care for at times, particularly in the morning. In speaking to the wife we found out that he loves to sing and that he was a choir member for years in his young days. So we came up with the idea to get him a CD player and the family brought in some music. We put that on every morning just prior to care and most times he sings along as loud as anything. It makes it less difficult to care for him and you know, sometimes we sing along with him and he just gets right into it. He enjoys singing and it is nice for us to see him express himself in this way. So it's like the woman in the play who weaves. Despite their cognitive impairment they can express themselves in creative ways.

A recreational therapist similarly commented on the creative expression of a resident in her arts program:

There's one woman I'm thinking of from my practice who no longer speaks and who is so cognitively impaired she can't walk or dress or feed herself. But when she comes to my program and sits at her easel you wouldn't know of her impairment. She paints beautifully with water colours. It's as if she's communicating through her art. 
The focus group participants further recognized embodied of expressions of selfhood in the singing and painting by the residents in the above examples. In these examples, the residents' creativity rests not upon an intellectual function, but rather on an embodied know-how and practical involvement. The ability to sing and to paint is incorporated into selfhood, which is itself embodied, and in turn selfhood is evoked through the body's pre-reflective capacity to express itself in subsequent enactment of these activities.

In all of the above recounted instances, the focus group participants clearly made a connection between scenes of the play and instances from their own practice, a connection that conveys both their understanding of the play and the relevance that the scenes depicted in the play have for dementia care.

Raised awareness of the significance of ritual and ceremony

Participants also stated that the play raised their awareness of the different ways persons with Alzheimer's disease express themselves. One of the scenes of the play depicts a Hanukkah party for residents on an Alzheimer Support Unit. After the ceremonial lighting of the Menorah the residents are taken back to their rooms with the exception of one resident who insists on staying. Her insistence to stay appears inexplicable amidst everyone's eagerness to return to their rooms. As staff are busy accompanying the other residents, this particular woman makes her way over to the Menorah where she says a prayer to herself while embracing the warmth of the candlelight. When a staff person returns for her, this time she does not resist. A physiotherapist, in commenting on this scene noted the following:

I never really thought about this personal or spiritual need that people with dementia might have. This scene was very powerful for me because it made me realize that prayer, communion, ceremony, etcetera, are important even for people with dementia. 
Echoing these comments an occupational therapist stated:

We have a chapel in our facility but I've never seen anyone go down there. But what are we denying residents by not facilitating some organized prayer for them? The scene with the Menorah made me think that maybe residents need some form of spiritual outlet that we should provide. Maybe like an organized social program? Or maybe we should bring the chapel to them for prayer.

A recreational therapist was particularly moved by this scene because, as she explains, it vividly depicts the need for personal prayer, a need that she was not previously aware of and thus has not accommodated in similar such programs of hers.

I organize a Hanukkah party just like what we saw in the play and it saddens me to think how many times residents might feel the need to get close to the Menorah but this is never recognized. There's always chaos when the program ends and staff have to take the residents back to the unit. But to be able to step back and see what we are all missing in this chaos was very powerful. That scene really hit home for me because look at how peaceful the woman was at the end of the scene because she had the chance to say a prayer at the Menorah. She was resisting the staff before because she wanted to say her prayer. And once she did she was fine. When I think about how many programs I've organized just like that one and how many times such a need might have been missed. We really have to pay attention to this [emphasis in original expression].

The participants in the above three quotations describe how the play raised their awareness by allowing them to "see" a spiritual need through the enactment of a ritual practice by persons with dementia, a need that they were not previously aware of. The power of the play to render visible to practitioners what was not visible to them before was further confirmed by many of the survey responses noted in the following section.

\section{Survey data}

Forty-two of forty-three (98\%) post-performance surveys were completed. Respondents reported a relevance of the production to their own practice with the majority $(97.6 \%)$ of participants agreeing or strongly agreeing that the play reminded them of experiences from their own practice. Respondents who disagreed with this statement (2.4\%) noted in the survey that the play did not remind them of experiences from their own practice because in their experience 
their client population exhibits more aggressive behaviour than what was depicted in the play. There was $83.3 \%$ agreement or strong agreement that seeing the play raised their awareness of the various ways that persons with Alzheimer's disease express themselves. Furthermore, 92.9\% agreed or strongly agreed that seeing the play raised their awareness of the different ways in which they interact with their cognitively impaired care recipients. Increased awareness was reported by all respondents $(100 \%)$ who agreed or strongly agreed that seeing the play made them aware of the need for staff to recognize and respond positively to patients' bodily movements and gestures in the context of dementia care. Respondents (97.6\%) strongly endorsed the use of drama as an educational tool for dementia care by agreeing or strongly agreeing that research-based drama would be an effective way to educate staff about dementia care practices.

Open-ended comments about what was most helpful and/or interesting about the play affirmed the value of observing enacted clinical interactions between care providers and recipients:

Seeing clinical situations enacted is an excellent way to be able to observe what we do both positive and negative - and to learn from that.

The strong comparison to actual practice allowed us to take a step back and see what we do. There often isn't the opportunity for such reflection in clinical practice but it's so crucial.

Seeing professional behaviour, both positive and negative, mirrored back to me was extremely powerful.

Practitioners don't often realize how they come across in their interactions with people with dementia. Seeing clinical situations enacted is an excellent way to be able to understand the impact of our behaviours on clients.

Many of the comments addressed the potential that the dramatic production has for changing practice: 
It gave ideas of how people with dementia can express personhood and how we as staff have to be more open-minded about our approach to care when faced with challenging behaviour.

Most valuable were the moments of insight into the meaning of patients' resistance to care and how this knowledge can change our practice.

I think if the play were to be shown on a monthly basis it would be an excellent reminder to staff about the humanity of our clients which would better their practice.

In allowing us to 'see' behaviours and the caregiver's reaction, the play is an excellent educational tool to identify bad habits and reinforce good ones.

No respondents indicated that there was anything unhelpful or uninteresting about the play.

There were, however, some constructive comments made regarding the scenes of the play. For example, some participants felt that the play was not representative enough of the experience of

Alzheimer's disease as expressed in the following comments:

The play should include more physically/verbally abusive behaviour typical in severe stages of Alzheimer's. On my unit this is all we see so it would be helpful if scenes in the play could portray this reality.

Because we only have male patients it would have been helpful to see some scenes focus on male behaviour.

Others noted that the play was not critical enough of the depersonalizing tendencies of some caregiving relationships:

It would be good to have some more extreme situations illustrating how staff ignore personhood and objectify clients.

Exposing more of the damaging aspects of care that result from denying personhood would be instructive.

\section{Discussion}

The evaluative data presented here suggests that drama was effective as a pedagogical tool in providing an accessible presentation of research on embodied selfhood to focus group participants. Expressions of Personhood in Alzheimer's features examples of selfhood that are 
rooted in a theoretical framework of embodiment (Kontos, 2003, 2004, 2005, 2006a, 2006b), which integrates Merleau-Ponty's (1962) radical reconceptualisation of perception and Bourdieu's $(1977 ; 1990)$ theory of the logic of practice. The value of using drama as an alternative dissemination strategy was that it facilitated a discussion about embodiment without any recourse to the theoretical bearings of the concept. Not only would a theoretical discussion have been difficult given the different disciplinary and clinical backgrounds of the focus group participants, but resorting to academic prose would have muted the physical, emotional, and sensory dimensions of communication so aptly depicted in the production, thereby flattening out "the flux of human relationships, the ways meanings are created intersubjectively as well as intertextually, embodied in gestures as well as in words..." (Jackson quoted in Conquergood, 1991, p. 188). In contrast, dramatic performance privileges the phenomenological complexity of everyday life and recovers the experiential immediacy of the body that was present in the original data-gathering situation. This allowed us to "evoke" rather than to "represent" experience (Tyler, 1987) and allowed for sympathetic exploration as well as critical examination of assumptions about personhood.

Furthermore, the dramatic portrayal of interactions between care staff and persons with Alzheimer's disease facilitated the recognition by staff of opportunities to respond to, and support bodily expressions of selfhood by persons with cognitive impairment. The representation of health care staff in their daily care giving practice together with the vivid depiction of manifestations of embodied selfhood fostered understanding amongst the focus group participants that catalyzed the discussion about the importance of nonverbal selfexpression by persons with severe cognitive impairment. The discussion confirmed the 
importance of recognizing and responding positively to such expressions for person-centred dementia care.

The translation of qualitative research into dramatic form fosters the emotional engagement of audiences through the audience's awareness that the staged re-presentations they are witnessing are based upon actual events. In the case of the production Expressions of Personhood in Alzheimer's, performed re-presentations were of actual self-expressions by persons who are severely cognitively impaired, which we believe increased the validity of the production and strengthened its perceived relevance. As Gray et al. (2000) argue, theatre can certainly be profound without a research base, however audiences such as health practitioners who are oriented towards empiricism appear to be more receptive when they know that the production is based on data accumulated within the scientific traditions of inquiry. The research foundation for the production Handle with Care? was, according to Gray et al. (2000) crucial for ensuring audiences a sense of relevance. Perceived relevance is of no small significance for it is critical for successful uptake of new knowledge and practice change.

Long-term care programs across Canada now mandate person-centred approaches to care (Chan \& Kenny, 2001) and yet large proportions of nursing home residents with Alzheimer's disease still receive tranquillizers for behavioural symptoms (Margallo-Lana et al., 2001) despite evidence of only modest efficacy, high placebo response (DeDeyn et al., 1999; Street et al., 2000), and serious adverse consequences (Sink, Holden, \& Yaffe, 2005). The overuse of tranquillizers (Douglas et al., 2004; Margallo-Lana et al., 2001) and other forms of restraint such as bed rails (Hamers, Gulpers, \& Strick, 2004) underscores a gap that exists between research in the area of person-centred dementia care and its incorporation into clinical practice. This research-practice gap results largely from the absence of appropriate knowledge translation 
methods for health care practitioners (Dewing, 2004; McCormack, 2004). Research indicates that knowledge translation is more successful when it consists of multifaceted (Bero et al., 1998), multi-component (Grol, 1997), and interactive educational interventions (O'Brien et al., 2001; Viau, 1994). The limitations of passive educational approaches to promote practice change are increasingly recognized (Grimshaw et al., 2003; O'Brien et al., 2001; Saltmarche, Kolodny, \& Mitchell, 1998), and, in response, experiential learning techniques such as role-play are being utilized with greater frequency (Comer, 2005; Williams, Kemper, \& Hummert, 2003). Drama has a uniquely compelling emotional quality that engages audiences on both an affective and cognitive level, which is said to be central to the success of educational interventions for medical training (Lorenz et al., 2004; Rosenbaum et al., 2005; Shapiro \& Hunt, 2003).

The results of our study demonstrate the effectiveness of Expressions of Personhood in Alzheimer's in fostering awareness and enhancing understanding amongst health care practitioners about the ways that persons with dementia use their bodies to express themselves. Given this effectiveness, dramatic performance holds promise as a strategy to facilitate our larger agenda to create a new ethic of dementia care that respects individuals with Alzheimer's disease as embodied beings deserving of dignity and worth. 


\section{Acknowledgments}

This study was generously funded by the Collaborative Research Program: Rehabilitation \& Long-Term Care, the Canadian Nurses Foundation, and the Nursing Care Partnership. Dr. Kontos is supported by the Canadian Institutes of Health Research Fellowship Program, and the Health Care, Technology, \& Place (HCTP) CIHR Strategic Research \& Training Program (supported by CIHR Institutes of Health Services and Policy Research, Gender and Health, and Knowledge Translation Secretariat). Dr. Naglie is supported by the Mary Trimmer Chair in Geriatric Medicine Research, University of Toronto. Toronto Rehabilitation is supported by a grant from the Ontario Ministry of Health and Long-Term Care. The views expressed here do not necessarily reflect those of our supporters or funders.

\section{Notes}

${ }^{1}$ CIHR is the major public agency responsible for funding health research in Canada.

${ }^{2}$ For a discussion of the various stages of the development of this production including script writing, meetings with the artistic troupe to explore the findings of the original research, as well as the methodological challenges of bringing the body-based theoretical framework explicit in the scripts to the stage see Kontos and Naglie (2006).

${ }^{3}$ Person-centred care is a philosophy that focuses on environmental and social causes of behavioural problems in dementia (Cohen-Mansfield \& Mintzer, 2005). Behavioural therapy is the standard non-pharmacological approach to suppressing or eliminating challenging behaviours in Alzheimer's disease (Douglas, James, \& Ballard, 2004). This involves assessing the triggers of the behaviour and their consequences, and designing an appropriate intervention (Emerson, 1998). Treatment approaches that are based on the evaluation and care of unmet needs of the person with Alzheimer's disease is central to person-centred care (Cohen-Mansfield \& Mintzer, 2005).

${ }^{4}$ For a more extensive analysis and discussion of these ethnographic examples of embodied selfhood see (Kontos, 2004, 2006a). 
${ }^{5}$ Though physicians deal with the body, medical practice is constructed in such a way as to confine direct bodywork to the activity of diagnosis or to mediate it by high-tech machines (Twigg, 2000).

${ }^{6}$ It should be noted that the term embodied selfhood was not introduced in the discussion or in the survey because at this stage of our research we wished to rely upon the participants' own interpretations of the expressions depicted in the play.

${ }^{7}$ The distribution of the survey after the focus group discussions could raise some doubt about whether it was the dramatic performance or the discussion following the performance that led to the findings reported here. However, the participants' responses in the focus group discussions, as reported in the 'findings' section, should minimize any doubt about the power of the play as a catalyst in raising awareness and prompting reflection. That the survey results largely reflect the very statements made by participants regarding the impact of the play should further minimize doubt about the validity of these findings. 


\section{References}

Abma, T.A. (2002). Emerging narrative forms of knowledge representation in the health sciences: Two texts in a postmodern context. Qualitative Health Research, 12(1), 5-27.

Acuna, L.E. (2000). Don't cry for us Argentineans: Two decades of teaching medical humanities. Medical Humanities, 26, 66-70.

Allen-Burge, R., Stevens, A.B., \& Burgio, I.D. (1999). Effective behavioral interventions for decreasing dementia-related challenging behavior in nursing homes. International Journal of Geriatric Psychiatry, 14, 213-232.

Bero, L.A., Grimshaw, J.M., Harvey, E., Oxman, A.D., \& Thomson, M. (1998). Closing the gap between research and practice: An overview of systematic reviews of interventions to promote the implementation of research findings. British Medical Journal, 317(7156), 465-468.

Bourdieu, P. (1977). Outline of a theory of practice. Cambridge: Cambridge University Press.

Bourdieu, P. (1990). The logic of practice. Cambridge: Polity Press.

Brodaty, H. (1996). Caregivers and behavioural disturbances: Effects and interventions. International Psychogeriatrics, 8(Suppl.3), 455-458.

Brodaty, H., Green, A., \& Koschera, A. (2003). Meta-analysis of psychosocial interventions for caregivers of people with dementia. Journal of the American Geriatrics Society, 51, 657664.

Chan, P., \& Kenny, S.R. (2001). National consistency and provincial diversity in delivery of long-term care in Canada. Journal of Aging \& Social Policy, 13(2/3), 83-99. 
Charon, R., Banks, J.T., Connelly, J.E., Hawkins, A.H., Hunter, K.M., Jones, A.H., et al. (1995). Literature and medicine: Contributions to clinical practice. Annals of Internal Medicine, 122(8), 599-606.

Clifford, J. (1986). Introduction: Partial truths. In J. Clifford, \& G. Marcus (Eds.), Writing culture: The poetics and politics of ethnography (pp. 1-26). Berkeley: University of California Press.

Clifford, J. (1988). Predicament of culture. Cambridge: Harvard University Press.

Cohen-Mansfield, J., \& Mintzer, J.E. (2005). Time for change: The role of nonpharmacological interventions in treating behavior problems in nursing home residents with dementia. Alzheimer Disease and Associated Disorders, 19(1), 37-40.

Comer, S.K. (2005). Patient care simulations: Role playing to enhance clinical understanding. Nursing Education Perspectives, 26(6), 357-361.

Conquergood, D. (1991). Rethinking ethnography: Towards a critical cultural politics. Communication Monographs, 58(June), 179-194.

Cooley, C.H. (1972). The looking glass self. In J. Manis, \& A. Meltzer (Eds.), Symbolic interaction (pp. 231-233). Boston: Allyn \& Bacon.

Davis, D. (2004). Dementia: Sociological and philosophical constructions. Social Science and Medicine, 58, 369-378.

DeDeyn, P.P., Rabheru, K., Rasmussen, A., Bocksberger, J.P., Dautzenberg, P.L., Eriksson, S., et al. (1999). A randomized trial of risperidone, placebo and haloperidol for behavioral symptoms of dementia. Neurology, 53, 946-955.

Deloney, L.A., \& Graham, C.J. (2003). Wit: Using drama to teach first-year medical students about empathy and compassion. Teaching and Learning in Medicine, 15(4), 247-251. 
Denzin, N. (1997). Interpretive ethnography: Ethnographic practices for the 21st century. Thousand Oaks: SAGE.

Denzin, N. (2000). Aesthetics and the practices of qualitative inquiry. Qualitative Inquiry, 6(2), 256-265.

Denzin, N.K., \& Lincoln, Y.S. (1998). Collecting and interpreting qualitative materials. Thousand Oaks, Calif.: SAGE.

Dewing, J. (2004). Concerns relating to the application of frameworks to promote personcentredness in nursing with older people. Journal of Clinical Nursing, 13(S1), 39-44.

Douglas, S., James, I., \& Ballard, C. (2004). Non-pharmacological interventions in dementia. Advances in Psychiatric Treatment, 10, 171-179.

Dröes, R. (1997). Psychosocial treatment for demented patients: Overview of methods and effects. In B.M.L. Miesen, \& G.M.M. Jones (Eds.), Care-giving in dementia: Research and applications (pp. 127-148). London: Routledge.

Easton, K. (1999). Using focus groups in rehabilitation nursing. Rehabilitation Nursing, 24(5), 212-215.

Emerson, E. (1998). Working with people with challenging behaviour. In E. Emerson,C. Hatton,J. Bromley, \& et al. (Eds.), Clinical psychology and people with intellectual disabilities (pp. 127-153). Chichester: John Wiley \& Sons.

Finnema, E., Dröes, R., Ribbe, M.W., \& Tilburg, W. (2000). The effects of emotion-oriented approaches in the care for persons suffering from dementia: A review of the literature. International Journal of Geriatric Psychiatry, 15, 141-161.

Fontana, A., \& Smith, R.W. (1989). Alzheimer's disease victims: The 'unbecoming' of self and the normalization of competence. Sociological Perspectives, 32(1), 35-46. 
Fossey, J., Ballard, C., Juszczak, E., James, I., Alder, N., Jacoby, R., et al. (2006). Effect of enhanced psychosocial care on antipsychotic use in nursing home residents with severe dementia: Cluster randomised trial. BMJ, 332(7544), 756-761.

Goffman, E. (1963). Stigma: Notes on the management of spoiled identity. Englewood Cliff, NJ: Prentice Hall.

Golander, H., \& Raz, A.E. (1996). The mask of dementia: Images of 'demented residents' in a nursing ward. Ageing and Society, 16, 269-285.

Gray, R., Sinding, C., Ivonoffski, V., Fitch, M., Hampson, A., \& Greenberg, M. (2000). The use of research-based theatre in a project related to metastatic breast cancer. Health Expectations, 3, 137-144.

Gray, R., Sinding, C., \& Fitch, M. (2001). Navigating the social context of metastatic breast cancer: Reflections on a project linking research to drama. Health, 5(2), 233-248.

Gray, R., Fitch, M., Labrecque, M., \& Greenberg, M. (2003). Reactions of health professionals to a research-based theatre production. Journal of Cancer Education, 18(4), 223-229.

Grimshaw, J.M., McAuley, L., Bero, L.A., Grilli, R., Oxman, A.D., Ramsay, C., et al. (2003). Systematic reviews of the effectiveness of quality improvement strategies and programmes. Quality Safety in Health Care, 12, 298-303.

Grol, R. (1997). Beliefs and evidence in changing clinical practice. British Medical Journal, 315(7105), 418-421.

Hamers, J., Gulpers, M., \& Strick, W. (2004). Use of physical restraints with cognitively impaired nursing home residents. Journal of Advanced Nursing, 45, 246-251. 
Haupt, M., Karger, A., \& Jänner, M. (2000). Improvement of agitation and anxiety in demented patients after psychoeducative group intervention with their caregivers. International Journal of Geriatric Psychiatry, 15, 1125-1129.

Henderson, J.A., \& Vesperi, M.D. (1995). The culture of long term care: Nursing home ethnography. New York: Bergin and Garvey.

Jonas-Simpson, C. (2001). From silence to voice: Knowledge, values, and beliefs guiding healthcare practices with persons living with dementia. Nursing Science Quarterly, 14(4), 304-310.

Kitwood, T. (1990). The dialectics of dementia: With particular reference to Alzheimer's disease. Ageing and Society, 10, 177-196.

Kitwood, T., \& Bredin, K. (1992). Towards a theory of dementia care: Personhood and wellbeing. Ageing and Society, 12, 269-287.

Kitwood, T. (1993). Towards the reconstruction of an organic mental disorder. In A. Radley (Ed.), Worlds of illness: Biographical and cultural perspectives on health and disease (pp. 143-160). London: Routledge.

Kitwood, T., \& Benson, S. (1995). The new culture of dementia care. London: Hawker.

Kitwood, T. (1997). Dementia reconsidered: The person comes first. Buckingham: Open University Press.

Kitwood, T. (1998). Toward a theory of dementia care: Ethics and interaction. Journal of Clinical Ethics, 9(1), 23-34.

Kitzinger, J. (1995). Qualitative research: Introducing focus groups. British Medical Journal, 311(7000), 299-302. 
Kontos, P. (2003). 'The painterly hand': Embodied consciousness and Alzheimer's disease. Journal of Aging Studies, 17, 151-170.

Kontos, P. (2004). Ethnographic reflections on selfhood, embodiment and Alzheimer's disease. Ageing and Society, 24, 829-849.

Kontos, P. (2005). Embodied selfhood in Alzheimer's disease: Rethinking person-centred care. Dementia: The International Journal of Social Research and Practice, 4(4), 553-570.

Kontos, P. (2006a). Embodied selfhood: An ethnographic exploration of Alzheimer's disease. In L. Cohen, \& A. Leibing (Eds.), Thinking about dementia: Culture, loss, and the anthropology of senility (pp. 195-217). Cambridge: Cambridge University Press.

Kontos, P. (2006b). Habitus: An incomplete account of human agency. American Journal of Semiotics, 22, 67-83.

Kontos, P., \& Naglie, G. (2006). "Expressions of personhood in Alzheimer's": Moving from ethnographic text to performing ethnography. Qualitative Research, 6(3), 301-317.

Krueger, R.A., \& Casey, M.A. (2000). Focus groups: A practical guide for applied research. Thousand Oaks: Sage.

Kuckartz, U. (1995). Case-oriented quantification. In U. Kelle (Ed.), Computer-aided qualitative data analysis (pp. 158-166). London: Sage.

Lorenz, K.A., Steckart, J.J., \& Rosenfeld, K.E. (2004). End-of-life education using the dramatic arts: The Wit educational initiative. Academic Medicine, 79(5), 481-486.

Lyman, K. (1989). Bringing the social back in: A critique of the biomedicalization of dementia. The Gerontologist, 29(5), 597-605.

Lyman, K. (1998). Living with Alzheimer's disease: The creation of meaning among persons with dementia. Journal of Clinical Ethics, 9(1), 49-57. 
Margallo-Lana, M., Swann, A., O'Brien, J., Fairbairn, A., Reichelt, K., Potkins, D., et al. (2001). Prevalence and pharmacological management of behavioural and psychological symptoms amongst dementia sufferers living in care environments. International Journal of Geriatric Psychiatry, 16, 39-44.

McCormack, B. (2004). Person-centredness in gerontological nursing: An overview of the literature. International Journal of Older People Nursing, 13(3a), 31-38.

Mead, G.H. (1970). Development of self through play and games. In G.P. Stone, \& H.A. Farberman (Eds.), Social psychology through symbolic interaction (pp. 537-545). London: Ginn-Blaisdell.

Merleau-Ponty, M. (1962). Phenomenology of perception. London: Routledge \& K. Paul.

Mienczakowski, J. (1992). Syncing out loud: A journey into illness. Brisbane, Australia: Griffith University Reprographics.

Mienczakowski, J., \& Morgan, S. (1993). Busting: The challenge of the drought spirit. Brisbane: Griffith University Reprographics.

Mienczakowski, J. (1999). Ethnography in the hands of participants: Tools of dramatic discovery. Studies in Educational Ethnography, 2, 145-161.

Mienczakowski, J., Smith, L., \& Morgan, S. (2002). Seeing words - hearing feelings: Ethnodrama and the performance of data. In C. Bagley, \& M. Cancienne (Eds.), Dancing the data (pp. 34-52). New York: Peter Lang.

Miles, M., \& Huberman, A. (1984). Qualitative data analysis. London: Sage.

Morton, I. (1999). Person-centred approaches to dementia care. Bicester: Winslow.

Nisker, J., Martin, D.K., Bluhm, R., \& Daar, A.S. (2006). Theatre as a public engagement tool for health-policy development. Health Policy, 78(2-3), 258-271. 
Nolan, M.R., Booth, A., \& Nolan, J. (1997). New directions in rehabilitation: Exploring the nursing contribution. London: English National Board for Nursing, Midwifery and Health Visiting.

Norris, S., \& Madore, O. (2000). Bill C-13: The Canadian Institutes of Health Research Act. Retrieved April 27, 2006, from http://www.parl.gc.ca/common/bills_ls.asp?lang=E\&ls=c13\&source=library_prb\&Parl=3 $6 \& \operatorname{Ses}=2$

Nussbaum, M. (1997). Cultivating humanity: A classical defense of reform in liberal education. Cambridge: Harvard University Press.

Nussbaum, M. (2004). Liberal education and global community. Liberal Education, 90(1), 4246.

O'Brien, M.A., Freemantle, N., Oxman, A.D., Wolf, F., Davis, D.A., \& Herrin, J. (2001). Continuing education meetings and workshops: Effects on professional practice and health care outcomes. The Cochrane Database of Systematic Reviews, 3, 1-35.

Paget, M. (1993). A complex sorrow: Reflections on cancer and an abbreviated life. Philadelphia: Temple University Press.

Pope, C., Ziebland, S., \& Mays, N. (2000). Qualitative research in health care: Analysing qualitative data. British Medical Journal, 320(7227), 114-116.

Rosenbaum, M.E., Ferguson, K.J., \& Herwaldt, L.A. (2005). In their own words: Presenting the patient's perspective using research-based theatre. Medical Education, 39, 622-631.

Sabat, S., \& Harré, R. (1992). The construction and deconstruction of self in Alzheimer's disease. Ageing and Society, 12, 443-461. 
Saltmarche, A., Kolodny, V., \& Mitchell, G. (1998). An educational approach for patientfocused care: Shifting attitudes and practice. Journal of Nursing Staff Development, 14(2), 81-86.

Sandelowski, M., Trimble, F., Woodard, E.K., \& Barroso, J. (2006). From synthesis to script: Transforming qualitative research findings for use in practice. Qualitative Health Research, 16(10), 1350-1370.

Shapiro, J., \& Hunt, L. (2003). All the world's a stage: Theatrical performance in medical education. Medical Education, 37(10), 922-927.

Sinding, C., Gray, R., Fitch, M., \& Greenberg, M. (2002). Staging breast cancer, rehearsing metastatic disease. Qualitative Health Research, 12(1), 61-73.

Sink, K.M., Holden, K.F., \& Yaffe, K. (2005). Pharmacological treatment of neuropsychiatric symptoms of dementia: A review of evidence. JAMA, 293, 596-608.

Sloane, P.D., Hoeffer, B., Mitchell, M., McKenzie, D.A., Barrick, A.L., Rader, J., et al. (2004). Effect of person-centered showering and the towel bath on bathing-associated aggression, agitation, and discomfort in nursing home residents with dementia: A randomized controlled trial. Journal of the American Geriatrics Society, 52, 1795-1804.

Street, J.S., Clark, W.S., Gannon, K.S., Cummings, J.L., Bymaster, F.P., Tamura, R.N., et al. (2000). Olanzapine treatment of psychotic and behavioural symptoms in patients with Alzheimer's disease in nursing care facilities: A double-blind randomised, placebocontrolled trial. Archives of General Psychiatry, 57, 968-976.

Tappen, R.M., Williams, C., Fishman, S., \& Touhy, T. (1999). Persistence of self in advanced Alzheimer's disease. Image: Journal of Nursing Scholarship, 31(2), 121-125.

Twigg, J. (2000). Bathing: The body and community care. London: Routledge. 
Tyler, S. (1987). The unspeakable: Discourse, dialogue and rhetoric in the postmodern world. Madison: University of Wisconsin Press.

Viau, P.A. (1994). Collaborative teaching-learning: A potential framework for staff development educators. Journal of Nursing Staff Development, 10(4), 195-201.

Williams, B., \& Grant, G. (1998). Defining 'people-centredness': Making the implicit explicit. Health and Social Care in the Community, 6, 84-94.

Williams, K., Kemper, S., \& Hummert, M.L. (2003). Improving nursing home communication: An intervention to reduce elderspeak. The Gerontologist, 43(2), 242-247. 